\title{
Carcinoma cuniculatum, un tumor infrecuente de localización habitualmente plantar
}

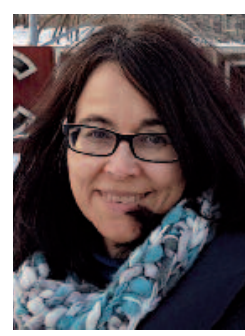

Beatriz García Bracamonte Facultativa especialista de área de Dermatología. Hospital Universitario 12 de Octubre. Madrid. Profesora asociada en Ciencias de la Salud. Universidad Complutense de Madrid.

\begin{abstract}
RESUMEN
El carcinoma cuniculatum, descrito por Aird en 1954, es un tumor muy infrecuente, de localización habitualmente plantar. Se considera una variedad de carcinoma epidermoide bien diferenciado, formado por un crecimiento epitelial de queratinocitos bien diferenciados, de aspecto banal. Afecta preferentemente a varones en la $5{ }^{\mathrm{a}}$ o $6{ }^{\mathrm{a}}$ décadas. Tiene un crecimiento lento y capacidad invasiva local, ya que crece en profundidad formando sinus y trayectos interconectados, afectando a las partes blandas e, incluso, al hueso. Es excepcional el desarrollo de metástasis. Su causa es desconocida, aunque se cree relacionado con el traumatismo, la irritación crónica y con el virus del papiloma humano (VPH). El tratamiento recomendado es la extirpación amplia. Debe ser incluido en el diagnóstico diferencial de las lesiones crónicas de localización plantar.
\end{abstract}

Palabras clave: carcinoma cuniculatum, epitelioma cuniculatum, carcinoma epidermoide de bajo grado, carcinoma escamoso de bajo grado, carcinoma escamoso bien diferenciado, carcinoma verrucoso, pie, plantar.

\section{ABSTRACT \\ Carcinoma cuniculatum, described by Aird in 1954, is an extremely rare indolent neoplasia that almost always arises on the foot. It is a variant of well-differentiated squamous cell carcinoma composed of banal keratinocytes. Most patients are male in their $5-6^{\text {th }}$ decades. Tumor increases slowly and squamous epithelium penetrates deeply underlying soft tissues and bone, forming duct-like formation and keratin-filled sinus- es. Metastasis are exceptional. Trauma, chronic irritation, and/or viral infection may play a role. Recommended treatment is wide local excision. It should be included in the differential diagnosis for chronic plantar lesions.}

Key words: carcinoma cuniculatum, epithelioma cuniculatum, low grade squamous cell carcinoma, well differenciated squamous cell carcinoma, verrucous carcinoma, foot, plantar.

\section{INTRODUCCIÓN}

El carcinoma cuniculatum es un tumor infrecuente descrito en 1954 por Aird et al. de localización habitualmente plantar. Se considera una variante rara de carcinoma epidermoide bien diferenciado y de bajo grado. Su agresi- vidad es local, pudiendo llegar a destruir partes blandas y hueso, siendo excepcional el desarrollo de metástasis ganglionares o a distancia.

En el presente artículo, se hace una revisión de la literatura existente de este raro tumor, aportando dos casos propios. 


\section{NUESTROS CASOS}

\section{Caso 1}

Mujer de 49 años que consulta en agosto de 2015 por una lesión en la planta del pie izquierdo de un año de evolución, de crecimiento lento, que le producía intenso dolor. Presentaba una lesión de $2,5 \times 2 \mathrm{~cm}$ de morfología redondeada en el antepié (fig. 1). Refería «un callo» en la misma localización desde hacía más de 10 años. La biopsia de la lesión fue informada como carcinoma cuniculatum (fig. 2). La resonancia magnética (RM)

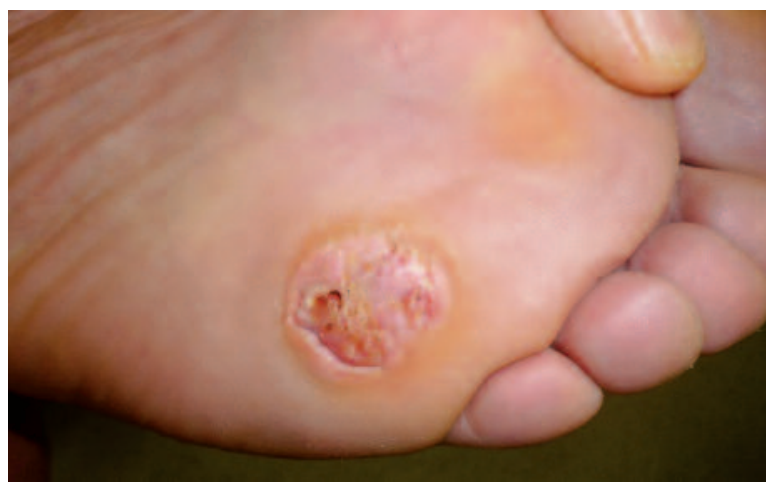

Figura 1. Lesión de $2,5 \times 2 \mathrm{~cm}$, de morfología redondeada, con collarete epidérmico, superficie irregular con orificios, áreas de superficie lisa, zonas con hiperqueratosis y otras ulceradas. La paciente refería un callo en dicha localización desde hace más de 10 años. Se aprecia una callosidad en la cercanía, a nivel del $2 .^{\circ}-3 .{ }^{\text {er }}$ dedo.

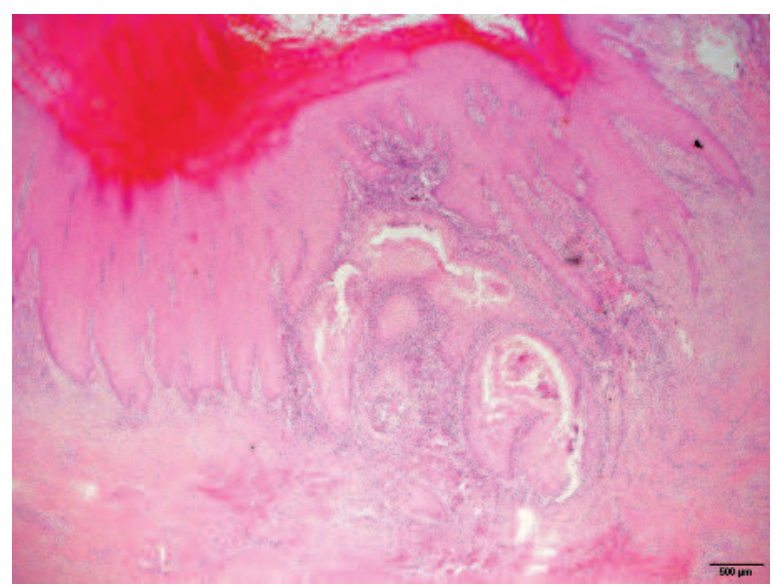

Figura 2. Se observa un epitelio hiperplásico de queratinocitos bien diferenciados con hiperqueratosis, que penetra en profundidad formando sinus (He $2 \mathrm{x}$ ). (fig. 3) objetivó la extensión de la lesión hasta contactar con la fascia plantar (y sobrepasarla), y contacto focal milimétrico con el tendón flexor del tercer dedo. Fue intervenida por el servicio de cirugía plástica, que realizó una amputación transmetatarsiana del tercer y cuarto dedos. Sin recidiva hasta la fecha tras cuatro años de seguimiento.

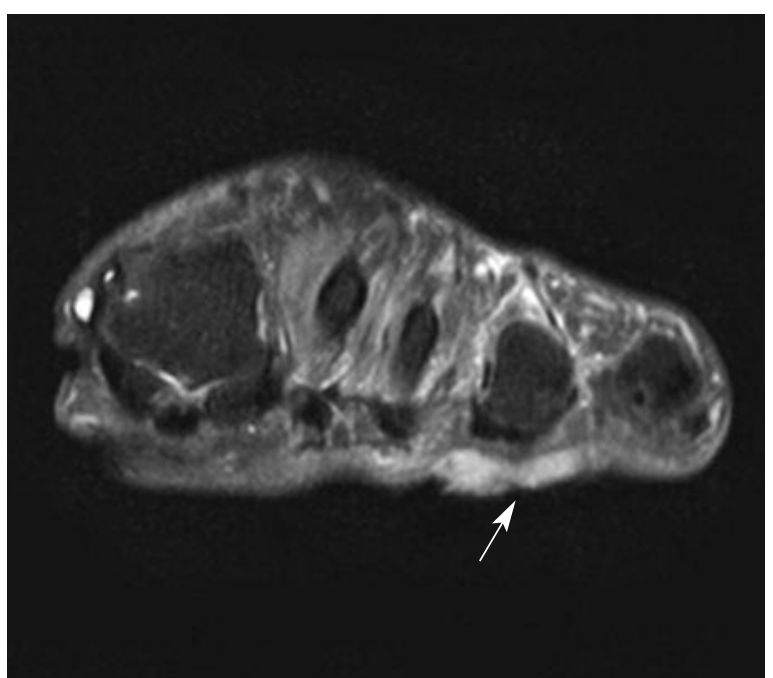

Figura 3. Resonancia magnética nuclear coronal en secuencia de densidad protónica con saturación grasa. La flecha señala la lesión, que se extiende hasta contactar con la fascia plantar (y sobrepasarla), y contacta focalmente con el tendón flexor del tercer dedo.

\section{Caso 2}

Varón de 63 años. Consulta en junio 2017 por una lesión de $3 \mathrm{~cm}$ en la planta del pie de más de 10 meses de evolución, muy dolorosa, que le impide la deambulación (fig. 4). Se le había realizado una biopsia cuatro meses antes, que solo demostró necrosis y tejido de granulación. Una nueva biopsia amplia y profunda fue informada como carcinoma cuniculatum (fig. 5). En la ecografía, se apreciaba un engrosamiento cutáneo y un área hipoecoica anfractuosa subcutánea de 3,2 × 1,6× $1,7 \mathrm{~cm}$, que alcanzaba en profundidad la fascia plantar. Fue intervenido por cirugía plástica, que realizó una extirpación con $1 \mathrm{~cm}$ de margen. Sin recidiva hasta la fecha tras dos años y medio de seguimiento. 


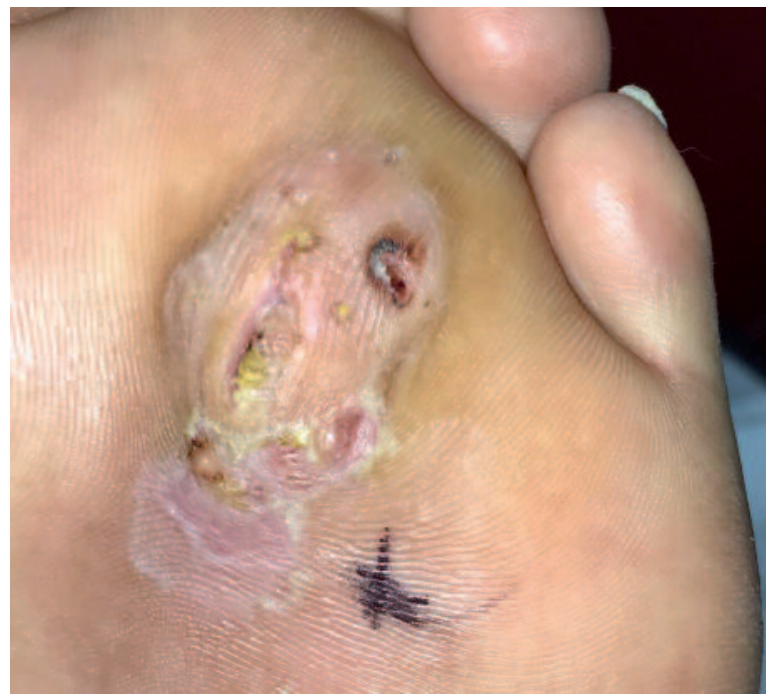

Figura 4. Lesión dolorosa de 10 meses de evolución en el antepié izquierdo, de $3 \mathrm{~cm}$, de superficie abollonada no verrucosa, con orificios de aspecto fistuloso. Se aprecia exudación y focos de queratina en los orificios.

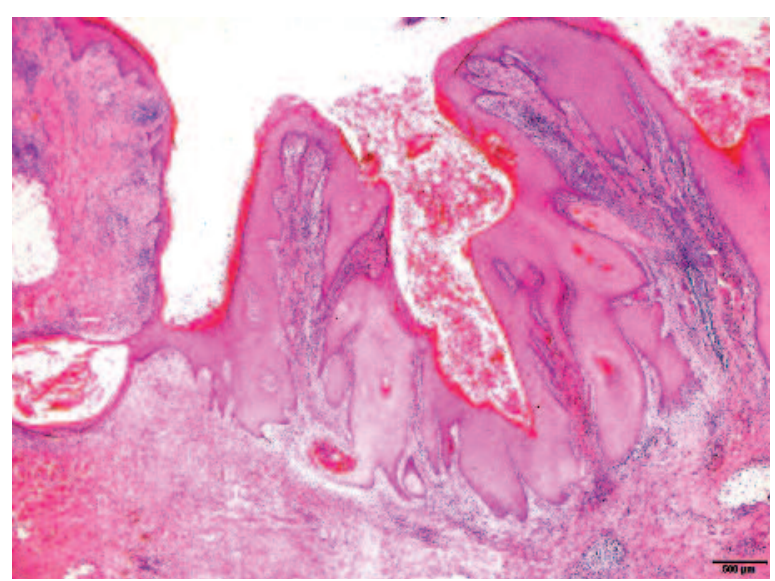

Figura 5. Proliferación epitelial de queratinocitos bien diferenciados, que penetra invaginándose y formando estructuras pseudoquísticas (He 2x).

\section{RECUERDO HISTÓRICO}

El carcinoma cuniculatum fue descrito por primera vez en 1954 por el cirujano británico Aird, como una variante poco frecuente de carcinoma epidermoide ${ }^{1}$. En el artículo original, se describen tres casos de pacientes (dos casos propios y un espécimen de museo) con lesiones similares en la planta del pie, que se describen clínicamente como «una masa bulbosa cubierta de piel con sinus y orificios, de consistencia blanda, y por la que, a la presión, drenaba material similar al sebo». Histológicamente, las lesiones presentaban un peculiar patrón arquitectónico de crecimiento en profundidad, formando canales y fístulas interconectadas, que «recuerdan a las estructuras de las madrigueras de los conejos» ${ }^{1,2}$. El epitelio que recubría los sinus era hiperplásico e irregular, pero bien diferenciado y de aspecto no neoplásico. Aird utilizó el término «epitelioma» cuniculatum para hacer referencia a que era una lesión que provenía del epitelio.

Unos años antes, el doctor Ackermann había descrito el carcinoma verrucoso como una variedad de carcinoma epidermoide de bajo grado, y es en 1976 cuando Brownstein y Shapiro consideran el carcinoma cuniculatum como una variedad de carcinoma verrucoso ${ }^{3}$, lo que ha llevado a cierto grado de confusión en la literatura, y dificulta la revisión de los casos descritos, ya que se han publicado muchos artículos en los que se utiliza y se sigue utilizando el término cuniculatum como sinónimo de carcinoma verrucoso de localización plantar ${ }^{49}$.

Pero no todos los autores están de acuerdo en aceptar esta sinonimia, y defienden de forma razonada que el auténtico carcinoma cuniculatum descrito por Aird es diferente del carcinoma verrucoso, tanto clínica como histológicamente ${ }^{2,10,11}$.

Steffen, en el año 2006, más de 50 años después de la descripción original, revisa de forma extensa los casos publicados hasta la fecha de carcinoma cuniculatum y llega a la conclusión de que la mayoría de los casos comunicados no se corresponden con la descripción original, y solo encuentra uno o dos casos que cumplan de forma completa los criterios clínicos e histológicos de Aird. Concluye en su artículo que es un tumor muy raro y defiende reservar el término cuniculatum solo para los tumores que se correspondan con la descripción original y denominar al resto simplemente carcinomas verrucosos plantares ${ }^{2}$.

Kubik y Rhatigan, en 2012, también defienden esta misma idea en su artículo «Carcinoma cuni- 
culatum: not a verrucous carcinoma», argumentando que, aunque ambos son variantes de carcinoma escamoso de bajo grado, el carcinoma cuniculatum descrito por Aird no es una lesión verrucosa ${ }^{10}$.

Recientemente, Kunc y Biernat (2019) han vuelto a incidir en esta controversia y han propuesto unos criterios diagnósticos histológicos basándose en la descripción original de Aird ${ }^{11}$.

Sin embargo, el significado clínico real de esta controversia no parece crucial, ya que, al tratarse ambos de carcinomas epidermoides de bajo grado y bien diferenciados, el tratamiento y curso clínico de ambas entidades (cuniculatum o verrucoso) es similar ${ }^{11}$.

\section{GENERALIDADES}

$\mathrm{Su}$ incidencia es desconocida. La gran mayoría de los artículos publicados describen casos aisla- dos, y las revisiones de casos de la literatura tienen el factor de confusión de agrupar tumores verrucosos con lo que podríamos llamar auténticos cuniculatum. Miller et al., en su revisión de 2001, encuentran 162 casos de tumores verrucosos plan$\operatorname{tares}^{12}$, mientras que Steffen, años después, afirma que, de los casos publicados, apenas uno o máximo dos ${ }^{13}$ coinciden con lo descrito por Aird ${ }^{2}$.

Kao et al. publican en la revista Cancer en 1982 una revisión con 46 casos propios (encontrados en su base de datos de 1500 epidermoides e hiperplasias pseudoepiteliomatosas de manos o pies diagnosticados entre 1950 y 1980) y 30 extraídos de la revisión de la literatura ${ }^{5}$. Ya se ha comentado que, en 2001, Miller et al. publican dos casos propios y hacen una revisión de los carcinomas verrucosos de pie publicados hasta la fecha en lengua inglesa (162 casos), aunque luego solo utilizan para su estadística $65^{12}$ (tabla 1 ).

Tabla 1. Carcinoma cuniculatum/verrucoso plantar: características de la mayor serie y dos revisiones de casos

\begin{tabular}{l|c|c|c}
\hline & Casos propios & $\begin{array}{c}\text { Revisión de casos } \\
\text { hasta 19805 }\end{array}$ & $\begin{array}{c}\text { Revisión de casos hasta } \\
\mathbf{2 0 0 1}^{\mathbf{1 2} *}\end{array}$ \\
\hline N. ${ }^{\circ}$ de pacientes & 46 & 30 & 60 \\
\hline Intervalo de edad [años] & $37-89$ & $40-71$ & $22-88$ \\
\hline Media de edad [años] & 60 & 54 & 59
\end{tabular}

Sexo

\begin{tabular}{|c|c|c|c|}
\hline Varón [n (\%)] & $39(84)$ & $23(79)$ & 42 \\
\hline Mujer $[\mathrm{n}(\%)]$ & $7(16)$ & $3(21)$ & 17 \\
\hline No conocido $[\mathrm{n}]$ & - & 4 & - \\
\hline Tiempo de evolución & 6 semanas-30 años & 3 meses-30 años & No especificado \\
\hline Media [años] & 4 & - & - \\
\hline Tamaño [cm] & $2-15$ & $1-12$ & - \\
\hline Media $[\mathrm{cm}]$ & 4,5 & - & - \\
\hline \multicolumn{4}{|l|}{ Localización } \\
\hline Pie $[\mathrm{n}(\%)]$ & $43(93,4)$ & $27(90)$ & $65(100) *$ \\
\hline Afectación ósea [n (\%)] & $5(10,8)$ & $2(5,7)$ & No especificado \\
\hline
\end{tabular}

*Su serie se centra exclusivamente en carcinomas verrucosos del pie y excluye muchos de los 162 casos que revisa. 
De ambos estudios, se puede concluir que es un tumor muy infrecuente que afecta en una mayor proporción a varones que a mujeres $(2,5$ 5,3:1) en la 5. ${ }^{\text {a } ~}$ $6 .^{\text {a }}$ décadas de la vida ${ }^{5,12,14,15}$. Miller et al. describen un leve predominio del pie derecho (55\%). Respecto a la raza, referida en 33 casos: 23 son blancos; 7, negros; 2, hispanos; y 1, polinesio.

El tiempo de evolución de la lesión varía de 6 semanas a 30 años, con una media de 4 años. El tamaño de la lesión oscila entre 2 y $15 \mathrm{~cm}$, con una media de $4,5 \mathrm{~cm}$.

La mayoría de las lesiones aparecen en el pie en zonas de apoyo.

En su serie, Kao et al. incluyen tres casos fuera del pie: pierna, nalga y palma de la mano.

Se han descrito tumores similares en otras mucosas (oral y genital) y localizaciones anatómicas.

\section{CLÍNICA}

Como se ha comentado, bajo el término cuniculatum, se han publicado casos de neoplasias de localización plantar de aspecto verrucoso, fungoide $\mathrm{o}$ «similares a coliflores» ${ }^{6-8}$ (figs. 6,7 y 8 ).

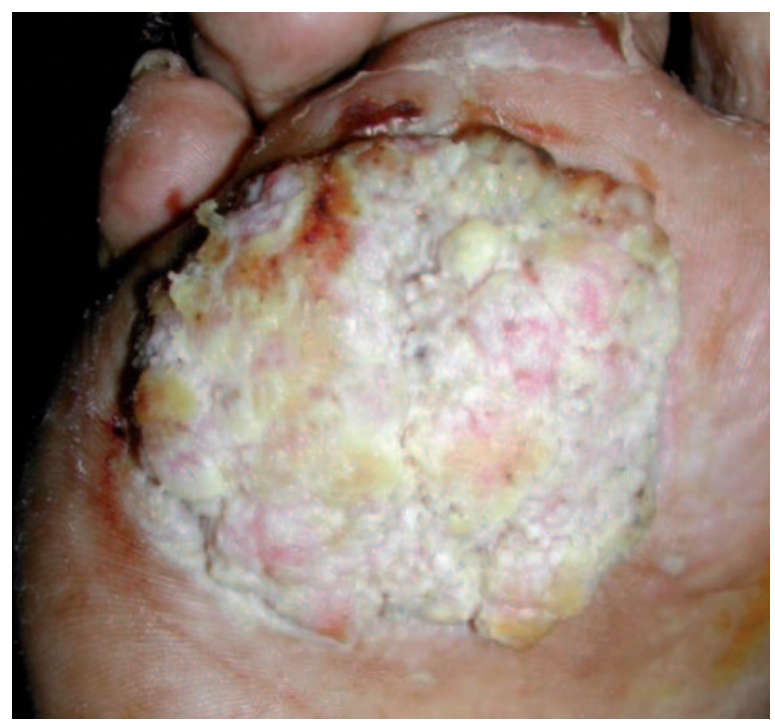

Figura 6. Masa vegetante localizada en el antepié.

(c) 2014 Mariem Mohamed, Hichem Belhadjali.

Mohamed M, Belhadjali H. Carcinoma cuniculatum of the foot arising on plantar callus. Pan Afr Med J. 2014;18:306.

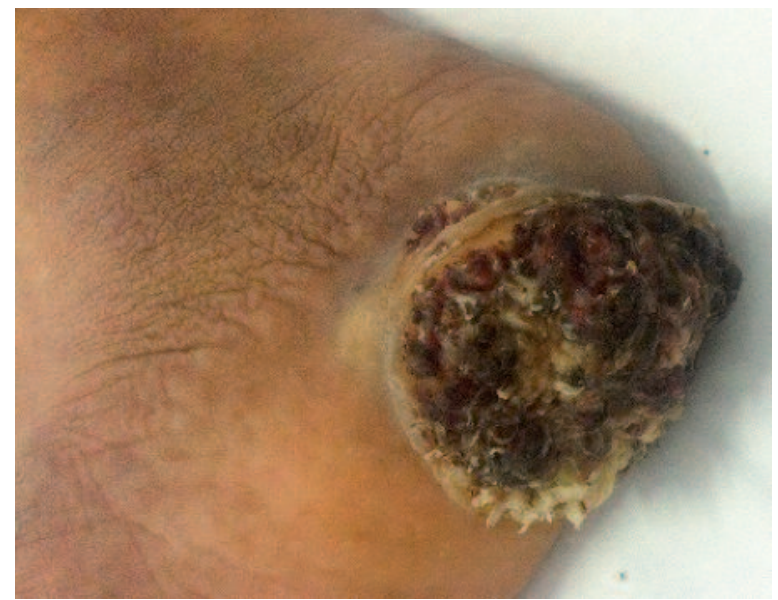

Figura 7. Lesión exofítica y de superficie verrucosa e hiperqueratósica localizada en el talón.

(c) 2016 Wassila Boumlil y Fouzia Hali.

Boumlil W, Hali1 F. Carcinome cuniculatum de la plante. Pan Afr Med J. 2016;24:92.

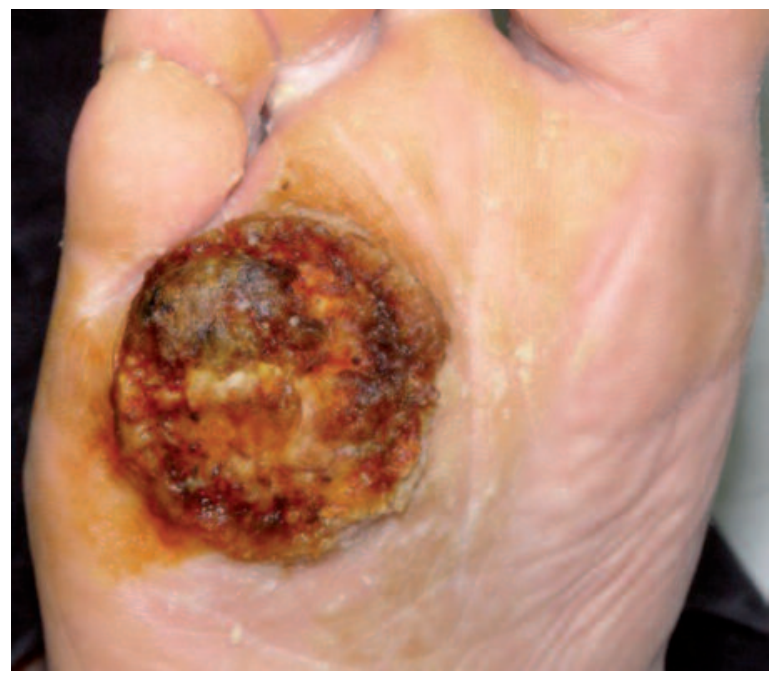

Figura 8. Lesión excrecente verrucosa de superficie hiperqueratósica en el antepié.

(C) 2011 Virginia Sanz Motilva y Antonio Martorell Calatayud.

Sanz Motilva V, Martorell Calatayud A. Un varón con una lesión verrucosa en el pie... (carcinoma verrucoso, epitelioma cuniculatum). Más Dermatol. 2011;14:14-16.

Si nos atenemos a la descripción original, el carcinoma cuniculatum es una lesión sobreelevada, polilobulada, no verrucosa, que presenta una superficie lisa levemente queratinizada, en la que se observan orificios y sinus, por los que puede drenar una exudación maloliente (figs. 1 y 4). 
Suelen ser lesiones de largo tiempo de evolución y dolorosas, que pueden dificultar la deambulación, tal y como ocurría en nuestros dos $\operatorname{casos}^{5,15}$, frecuentemente, interpretadas como verrugas plantares o callos que no responden al tratamiento o se sobreinfectan $8,15,16$.

El diagnóstico diferencial clínico se plantea con verrugas víricas, callos, poromas, porocarcinomas, queratoacantomas, sarcomas y melanomas amelanóticos, entre otros ${ }^{12}$.

La presencia de detritos y mal olor puede inducir a sospechar causas infecciosas tanto bacterianas como por otros microorganismos, y hay casos descritos en que se ha interpretado la afectación ósea como una osteomielitis ${ }^{14,16}$.

Se localiza en más de un $90 \%$ de los casos en la planta del pie, aunque, como ya se ha comentado, hay casos aislados en otras localizaciones como la eminencia tenar, las nalgas o las piernas ${ }^{5,11,17}$.

La lesión crece en profundidad afectando a las partes blandas y el hueso ${ }^{5,16}$.

\section{HISTOLOGÍA}

La histología muestra una proliferación de queratinocitos bien diferenciados de aspecto hiperplásico, pero no neoplásico. Presenta una arquitectura característica con invaginaciones tumorales que penetran en profundidad alcanzando partes blandas e, incluso, hueso, formando trayectos fistulosos interconectados que remedan las «madrigueras de los conejos». El término cuniculatum, de hecho, en latín significa «con forma de tubo o canal».

Los queratinocitos tienen un aspecto maduro con escasos focos de atipia celular, muy raras mitosis, sin pleomorfismo ${ }^{1,2,5}$. La presencia de anaplasia debe sugerir el diagnóstico de un verdadero carcinoma epidermoide.

El diagnóstico diferencial histológico se plantea con la hiperplasia pseudoepiteliomatosa y las hiperplasias epidérmicas reactivas a infecciones, úlceras o traumatismos. También se incluyen en el diagnóstico diferencial las verrugas víricas gigantes y el queratoacantoma ${ }^{5}$.
Como se ha comentado, Kunc y Biernat han propuesto unos criterios para poder diagnosticar el carcinoma cuniculatum tal y como lo describió Aird, remarcando que es una tumoración sobreelevada, la ausencia de proliferación verrucosa, la presencia de orificios y sinus recubiertos por un epitelio de aspecto no neoplásico, con criptas rellenas de láminas de queratina, con paraqueratosis aislada y con un estroma edematoso y mixoide ${ }^{11}$.

\section{DIAGNÓSTICO}

El diagnóstico es difícil y es habitual que se retrase varios meses - y, habitualmente, años-, ya que, inicialmente, pueden confundirse con verrugas plantares, callos $^{18}$, infecciones, osteomielitis ${ }^{14,16}$ o úlceras diabéticas ${ }^{7,19-22}$. El tiempo medio hasta el diagnóstico fue de 13 años en un estudio y de 16 años en otra serie de casos ${ }^{14}$.

El diagnóstico precisa de un anatomopatólogo experto, de una buena comunicación entre clínicos y anatomopatólogos y de una adecuada correlación clínico-histológica. Se han publicado muchos casos que han requerido más de una biopsia, tal y como ocurrió en uno de nuestros casos, ya que, al tratarse de una proliferación de queratinocitos bien diferenciados, una biopsia superficial puede no ser concluyente. Por lo tanto, todos los autores coinciden en aconsejar realizar biopsias incisionales amplias y profundas $1,2,12,14-16,21,23,24$.

\section{PRUEBAS DE IMAGEN}

Los casos publicados más recientes han utilizado como prueba de imagen la RM, y aconsejan su uso por ser de gran ayuda a la hora de planificar la cirugía $4,7,15,17$.

Casos descritos con anterioridad al desarrollo de la RM utilizaban la radiografía simple y, posteriormente, la tomografía axial computarizada (TAC) para valorar la afectación ósea.

Aunque se considera un tumor de bajo grado con agresividad solo local, se aconseja hacer un examen clínico minucioso y buscar adenopatías. En los distintos artículos revisados, se encuentran 
casos publicados en los que los autores han optado por realizar pruebas más generales para descartar metástasis a distancia, como ecografía ganglionar, abdominal ${ }^{15}$, TAC $^{14}$ o PET-TAC ${ }^{17}$ (tomografía por emisión de positrones-TAC).

\section{ETIOLOGÍA}

La causa se desconoce, pero se ha querido relacionar con el traumatismo y microtraumatismo repetido, con fenómenos inflamatorios crónicos y con el $\mathrm{VPH}^{5,14}$.

La gran mayoría de casos descritos se localizan en el antepié y otras zonas de apoyo y roce, por lo que se piensa que la irritación mecánica crónica puede desempeñar un papel importante ${ }^{11}$. Se han documentado casos desarrollados sobre cicatrices $^{25}$, muñones de amputación y áreas de queratodermia ${ }^{18}$. Algún autor ha planteado que se podría desarrollar sobre callos de larga evolución ${ }^{8}$ o verrugas ${ }^{26}$.

Respecto a la posible implicación del VPH, los resultados son poco consistentes y contradictorios. Se ha descrito la coexistencia en el mismo paciente de un carcinoma cuniculatum con verrugas vulgares clásicas y casos desarrollados sobre verrugas $^{12,26,27}$. Sin embargo, Kao et al., en su serie de 1980, no encuentran inclusiones ni partículas virales al microscopio electrónico, ni ácido desoxirribonucleico del VPH ${ }^{5}$. Tampoco se ha detectado por inmunohistoquímica en muchos casos publicados ${ }^{12,17,28}$. Pero también se han comunicado casos con posible relación con el VPH 2, 11, 16 y 18 7,19,20,22,29.

$\mathrm{Al}$ considerar los datos expuestos, no debemos olvidar la confusa agrupación en los artículos de verdaderos casos de cuniculatum con carcinomas verrucosos, lo que dificulta extraer conclusiones.

Se ha publicado también un caso aparecido en un paciente con artritis psoriásica en tratamiento con metotrexato y etanercept ${ }^{15}$.

\section{TRATAMIENTO}

El tratamiento es quirúrgico. Se recomienda una exéresis amplia con, al menos, $5 \mathrm{~mm}$ de margen libre, ya que las exéresis incompletas se asocian a frecuentes recidivas ${ }^{4}$. El cierre puede ser por segunda intención, injertos o colgajos ${ }^{12,15,27}$. Hay casos descritos tratados con cirugía de Mohs, ${ }^{7,30}$.

En aquellos casos en que el tumor invade el hueso, se considera necesaria la amputación ${ }^{6,8,14,23,25}$.

La radioterapia de forma clásica se ha considerado inapropiada por el posible riesgo de transformación de un carcinoma bien diferenciado en uno anaplásico, de peor pronóstico ${ }^{12,14}$.

\section{PRONÓSTICO}

El carcinoma cuniculatum se considera una variante de carcinoma epidermoide de bajo grado con agresividad local y muy bajo potencial metastásico. Las metástasis son extremadamente raras, aunque hay un caso recientemente publicado de localización tenar con metástasis óseas y ganglionares ${ }^{17}$.

Kao et al. describen en su serie tres casos que desarrollaron metástasis ganglionares en un período medio de dos años. Miller et al., en su revisión, encuentran dos casos más: el descrito por Owen et al. con afectación ganglionar y pulmonar, y el caso de McKee et al. con lesiones satélites en una pierna y ganglionares. Miller et al. postulan que estos casos no se corresponden con auténticos tumores verrucosos, sino con verdaderos carcinomas epidermoides ${ }^{12}$.

Kao et al. aportan datos en su serie del seguimiento de 26 de sus pacientes (de 1-19 años), 16 de los cuales quedaron libres de enfermedad, 8 fallecieron por otras causas, 3 casos tuvieron recurrencias locales (2 de ellos recurrencias múltiples) y 3 que desarrollaron las ya comentadas metástasis ganglionares. No refieren ningún caso de fallecimiento por enfermedad metastásica ${ }^{5}$.

Nuestros dos casos se encuentran libres de enfermedad 4 y 2,5 años después de la cirugía.

En cuanto al seguimiento, se recomienda realizar revisiones clínicas semestrales durante, al menos, 2 años ${ }^{14}$. 


\section{MENSAJES CLAVE}

El carcinoma cuniculatum es un tumor infrecuente que debe incluirse en el diagnóstico diferencial de lesiones crónicas de evolución tórpida localizadas en la región plantar. Su diagnóstico suele retrasarse, ya que es habitual que se confunda con patología banal o infecciosa.

Clínicamente, el auténtico cuniculatum es una lesión no verrucosa, con orificios y sinus, que crece en profundidad. Pero, en la literatura, se ha utilizado ampliamente el término cuniculatum como sinónimo de carcinoma verrucoso plantar.

Afecta con mayor frecuencia a varones de más de 55 años en zonas de apoyo.

El diagnóstico histológico es difícil; requiere un anatomopatólogo experto, una adecuada correlación clínico-patológica y biopsias amplias y profundas.

\section{BIBLIOGRAFÍA}

1. Aird I, Johnson HD, Lennox B, Stansfeld AG. Epithelioma cuniculatum: a variety of squamous carcinoma peculiar to the foot. Br J Surg. 1954;42(173):245-50.

2. Steffen C. Dermatopathology in historical perspective: epithelioma cuniculatum (Aird). Am J Dermatopathol. 2006;28(5): 451-61.

3. Brownstein MH, Shapiro L. Verrucous carcinoma of skin: epithelioma cuniculatum plantare. Cancer. 1976;38(4):1710-6.

4. Bhushan M, Ferguson JE, Hutchinson CE, Muston HL. Carcinoma cuniculatum of the foot assessed by magnetic resonance scanning. Clin Exp Dermatol. 2001;26(5):41922.

5. Kao GF, Graham JH, Helwig EB. Carcinoma cuniculatum (verrucous carcinoma of the skin): a clinicopathologic study of 46 cases with ultrastructural observations. Cancer. 1982;49(11): 2395-403.

6. Suen K, Wijeratne S, Patrikios J. An unusual case of bilateral verrucous carcinoma of the foot (epithelioma cuniculatum). J Surg Case Rep. 2012;2012(12).

7. Sanz Motilva $\mathrm{V}$, Martorell-Calatayud A. Un varón con una lesión verrucosa en el pie... (carcinoma verrucoso, epitelioma cuniculatum). Más Dermatol. 2011;14-6.

8. Mohamed M, Belhadjali $\mathrm{H}$. Carcinoma cuniculatum of the foot arising on plantar callus. Pan Afr Med J. 2014;18:306.

9. Boumlil W, Hali F. Carcinome cuniculatum de la plante. Pan Afr Med J. 2016;24:92.

10. Kubik MJ, Rhatigan RM. Carcinoma cuniculatum: not a verrucous carcinoma. J Cutan Pathol. 2012;39(12):1083-7.

11. Kunc M, Biernat W. Carcinoma cuniculatum of the lower leg: a case report and proposed diagnostic criteria. Am J Dermatopathol. 2019:41(11):855-7.

12. Miller SB, Brandes BA, Mahmarian RR, Durham JR. Verrucous carcinoma of the foot: a review and report of two cases. J Foot Ankle Surg. 2001;40(4):225-31.
13. Reingold IM, Smith BR, Graham JH. Epithelioma cuniculatum pedis, a variant of squamous cell carcinoma. Am J Clin Pathol. 1978;69(5):561-5.

14. Corbin V, Vidal M, Souteyrand P, D'Incan M, Amarger S, Laurichesse $\mathrm{H}$, et al. Carcinome cuniculatum : un diagnostic difficile, à évoquer devant une ostéite chronique d'évolution défavorable sous traitement. Rev Med Interne. 2006;27(9): 713-6.

15. Tchernev G, Guarneri C, Bevelacqua V, Wollina U. Carcinoma cuniculatum in course of etanercept: blocking autoimmunity but propagation of carcinogenesis? Int I Immunopathol Pharmacol. 2014;27(2):261-6.

16. Arisi M, Zane C, Edu I, Battocchio S, Petrilli G, Calzavara-Pinton PG. Carcinoma cuniculatum of the foot invading the bone mimicking a pseudo-epitheliomatous reaction to an acute osteomyelitis. Dermatol Ther (Heidelb). 2016;6(1):95-9.

17. Feldmann R, Wruhs M, Peinhaupt T, Stella A, Breier F, Steiner A. Carcinoma cuniculatum of the right thenar region with bone involvement and lymph node metastases. Case Rep Dermatol. 2017:9(3):225-30.

18. Affleck AG, Leach IH, Littlewood SM. Carcinoma cuniculatum arising in focal plantar keratoderma. Dermatol Surg. 2007; 33(6):745-8.

19. Floristán MU, Feltes RA, Sáenz JC, Herranz P. Carcinoma verrugoso del pie asociado a virus papiloma humano tipo 18. Actas Dermosifiliogr. 2009;100(5):433-35.

20. Noel JC, Peny MO, Detremmerie O, Verhest A, Heenen M, Thiry L, et al. Demonstration of human papillomavirus type 2 in a verrucous carcinoma of the foot. Dermatology. 1993; 187(1):58-61.

21. Schein O, Orenstein A, Bar-Meir E. Plantar verrucous carcinoma (epithelioma cuniculatum): rare form of the common wart. Isr Med Assoc J. 2006;8(12):885.

22. Wastiaux H, Dreno B. Recurrent cuniculatum squamous cell carcinoma of the fingers and virus. J Eur Acad Dermatol Venerol. 2008;22(5):627-8

23. Halpern J, Harris $S$, Suárez V, Jeyaratnam R, Smith AG. Epithelioma cuniculatum: a case report. Foot Ankle Surg. 2009;15(2):114-6.

24. Thomas EJ, Graves NC, Meritt SM. Carcinoma cuniculatum: an atypical presentation in the foot. J Foot Ankle Surg. 2014; 53(3):356-9.

25. Kunze E, Burchhardt H, Schweyer S, Thielke-Neitzel K. Carcinoma cuniculatum plantare im Bereich einer mechanisch-traumatisch verursachten Hautnarbe: Versicherungsrechtliche Aspekte des Narbenkarzinoms. Unfallchirurg. 2006;109(9):809-14.

26. Wilkinson JD, McKee PH, Black MM, Whimster IW, Lovell D. A case of carcinoma cuniculatum with coexistant viral plantar wart. Clin Exp Dermatol. 1981;6(6):619-23.

27. Ray R, Bhagat A, Vasudevan B, Sridhar J, Madan R, Ray M. A rare case of plantar epithelioma cuniculatum arising from a wart. Indian J Dermatol. 2015;60(5):485-7.

28. Petersen CS, Sjølin KE, Rosman N, Lindeberg H. Lack of human papillomavirus DNA in carcinoma cuniculatum. Acta Derm Venereol. 1994;74(3):231-2.

29. Schell BJ, Rosen T, Rády P, Arany I, Tschen JA, Mack MF, et al. Verrucous carcinoma of the foot associated with human papillomavirus type 16. J Am Acad Dermatol. 2001;45(1): 49-55.

30. Mohs FE, Sahl WJ. Chemosurgery for verrucous carcinoma. J Dermatol Surg Oncol. 1979;5(4):302-6. 